\title{
Saúde sexual e reprodutiva na etnia Xukuru do Ororubá: diga às mulheres que avancem
}

\author{
Sexual and reproductive health in the Xukuru of Ororubá ethinic \\ group: tell the women to go forward
}

Maria Rafaela Amorim de Araujo', Mariane Silva Tavares², Vânia Rocha Fialho de Paiva e Souza², Diana de Oliveira Bezerra ${ }^{3}$

DOI: $10.1590 / 0103-1104202012414$

RESUMO Este estudo teve como objetivo conhecer as práticas em saúde sexual e reprodutiva de mulheres da etnia Xukuru do Ororubá. Trata-se de uma pesquisa descritiva exploratória, com abordagem qualitativa, que se utiliza da Teoria Transcultural do Cuidado. Foram entrevistadas 18 mulheres indígenas, na Aldeia de Cimbres, terra Xukuru, localizada na Serra do Ororubá, município de Pesqueira (PE). Foram codificadas quatro categorias analíticas, que contemplaram as categorias nativas/êmicas identificadas nos dados coletados: 1) Mulheres da etnia Xukuru do Ororubá e o lugar que ocupam; 2) Políticas de saúde e seu impacto na vida das mulheres indígenas; 3) Práticas em saúde sexual e reprodutiva; 4) Enfermagem: promoção à saúde e empoderamento. Frequentemente, ressalta-se a importância do feminino dentro dos povos indígenas, contudo, a relação entre homens e mulheres desagua em uma relação de poder desfavorável para as mulheres. O povo Xukuru do Ororubá encontra-se em uma situação sanitária e de saúde semelhante à população geral do Agreste e do Sertão pernambucano. As mulheres Xukuru do Ororubá fazem uso simultâneo e regular da biomedicina e da medicina indígena, contudo, sem uma real articulação. Urge o redirecionamento das práticas em saúde da mulher através da dinâmica da sensibilidade cultural.

PALAVRAS-CHAVE Saúde sexual e reprodutiva. População indígena. Enfermagem transcultural.

1Fundação Oswaldo Cruz (Fiocruz), Instituto Aggeu Magalhães (IAM) - Recife (PE), Brasil. rafaelaamorim.enf@gmail. com

2 Universidade de Pernambuco (UPE) - Recife (PE), Brasil.

3 Universidade Federal de Pernambuco (UFPE), Hospital das Clínicas (HC) - Recife (PE), Brasil.

\begin{abstract}
The aim of the current study is to get to know the sexual and reproduction health practices of women belonging to the Xukuru of Ororubá ethnic group. It followed a descriptive exploratory design, of qualitative approach, based on the Transcultural Care Theory. Eighteen indigenous women, from the Cimbres village, located in Xukuru of Ororubá territory, Pesqueira County (PE), were interviewed. Four analytical categories were coded, which included the native/emic categories identified in the data collected:1) Women belonging to the Xukuru of Ororuba ethnic group and the place they occupy; 2) Health policies and their impact on indigenous women's lives; 3) Practices in sexual and reproductive health; 4) Nursing: health promotion and empowerment. The importance of the female character inside indigenous populations is often highlighted, however, the different behavioral patterns and roles attributed to men and women still lies on power relations unfavorable to women. The Xukuru of Ororubá face sanitary and health conditions similar to that faced by the general population living in the Agreste and Hinterland regions of Pernambuco State. Xukuru of Ororubá women make regular and simultaneous use of biomedicine and indigenous medicine, however, without real articulation. There is an urgent need to redirect women-health practices in order to perform nursing practices based on a transcultural approach.
\end{abstract}

KEYWORDS Sexual and reproductive health. Indigenous population. Transcultural nursing. 


\section{Introdução}

Considerando o período colonial, berço da classificação racial como a conhecemos hoje, entende-se o cunho de sua criação como estratégia para a dominação de povos, baseada na ideia de existência de raças superiores e inferiores ${ }^{1}$. Sendo assim, os povos indígenas originários do Brasil, as pessoas negras traficadas e escravizadas, submetidos aos colonizadores europeus, participaram do desenvolvimento do capitalismo colonial à custa da exploração da sua força de trabalho, e da usurpação da terra e riquezas naturais ${ }^{2}$.

O processo de colonização trouxe vários problemas para a continuidade das culturas e dos costumes desses povos, ressignificando, por exemplo, o conceito de família e a atribuição de papeis sociais por gênero, marginalizando suas crenças com a imposição do padrão da Igreja Católica, através das missões evangelizadoras. Tal padrão consiste na ideia de representação dos corpos, estando a mulher subordinada ao homem, e o não branco subordinado ao branco, tornando a realidade da mulher não branca a mais desfavorável. Dessa forma, nasceu o modelo de sociedade perpetuado até os dias atuais, que mesmo com os avanços e lutas, ainda se baseia no machismo, racismo e eurocentrismo'.

Devido ao patriarcado arraigado desde a colonização, o lugar feminino vem sendo conquistado a curtos passos, iniciando com a participação das mulheres em espaços gerais, como a construção da Constituição cidadã, que marca a inserção mais evidente da mulher indígena na luta pelos seus direitos. Além desta, a Comissão de Professores Indígenas em Pernambuco e a Articulação dos Povos Indígenas no Nordeste, Minas Gerais e Espírito Santo (APOInME) também representam espaços conquistados pelas mulheres indígenas, que contaram com a Guerreira Maninha Xukuru-Kariri em sua construção².

Apesar de autores como Luciano ${ }^{3}$ (índio Baniwa e doutor em Antropologia Social) afirmarem que as mulheres indígenas não estão preocupadas com a conquista de espaços de liderança, estas vêm sentindo a necessidade de assumir o protagonismo nos debates, ainda que com dificuldades.

Falas como a de Dona Zenilda - reconhecida liderança e considerada mãe do povo Xukuru do Ororubá - ratificam a necessidade de superação das desigualdades vivenciadas pelas mulheres:

O movimento indígena precisa entender a importância das mulheres organizadas, mas é desafio das mulheres superar isso e se impor, se colocar como mulher mesmo. Os maridos reclamam muito das mulheres irem viajar, mas eu digo: onde tem confiança, tem cumplicidade2(44).

Nesse cenário, as indígenas vivenciam diariamente o enfrentamento do preconceito, por serem mulheres e por serem indígenas; lutam contra as desigualdades sociais, chegando a estarem presentes nos conselhos, nas representações e trabalhando nas instituições públicas ${ }^{2}$. Em junho de 2002, em Manaus (AM), aconteceu o I Encontro de Mulheres Indígenas da Amazônia Brasileira, no qual ocorreu o primeiro debate oficial sobre os direitos das mulheres, entre as populações indígenas brasileiras. No ano de 2006, em Brasília (DF), o debate ganhou esfera nacional durante o Encontro Nacional de Mulheres Indígenas, no qual foram definidas como prioridades três áreas temáticas: discriminação e violência; desenvolvimento econômico; e saúde 4 .

Já discutido em fóruns nacionais, o tema da saúde sexual e reprodutiva tem sido objeto de preocupação do movimento organizado de mulheres indígenas ${ }^{5}$. Observam-se condições pouco favoráveis para elas negociarem o sexo seguro, evitarem gravidezes e, em geral, para tomarem decisões quanto à sexualidade e reprodução, o que as deixa expostas a infecções de transmissão sexual e outros agravos ${ }^{6}$. Tem sido reivindicado que os direitos sexuais e reprodutivos das mulheres indígenas estejam de acordo com as tradições e culturas, desde que essas culturas não violentem as mulheres e que sejam reconhecidas pelas políticas públicas ${ }^{\mathbf{5}}$. 
Contudo, as concepções culturais dessas populações sobre corpo, fluidos corporais e reprodução ainda são pouco conhecidas ou pouco utilizadas pelo pessoal de saúde, para orientar sua prática ${ }^{6}$. Para chegar ao entendimento entre a cultura tradicional indígena e a cultura ocidental, as equipes de saúde devem ampliar sua bagagem de conhecimentos para além da biomedicina, e buscar a compreensão do cuidado transcultural. Como profissão responsável pelo cuidado embasado cientificamente, a enfermagem vem, ao longo das últimas décadas, buscando aprofundar discussões sobre sua prática ${ }^{7}$.

Desafiada pela complexidade dos seres humanos e seus diversos modos culturais de viver, Madeleine Leininger, enfermeira e antropóloga, desenvolveu um foco comparativo no campo da Enfermagem Transcultural, que foi definido como:

Subcampo ou ramo da enfermagem que enfoca o estudo comparativo e a análise de culturas com respeito à enfermagem e as práticas de cuidados de saúde-doença, às crenças e aos valores, com a meta de proporcionar um serviço de atendimento de enfermagem significativo e eficaz para as pessoas, de acordo com os seus valores culturais e seu contexto de saúde-doença ${ }^{8(16)}$.

De acordo com Camargo', a Teoria Transcultural do Cuidado tem sido utilizada com frequência no Brasil nas pesquisas de enfermagem, mas seu trabalho não registrou nenhuma abordagem acerca da saúde sexual e reprodutiva. Partindo disto, entende-se a relevância da presente pesquisa, que se propôs a trabalhar com tal temática, buscando analisar os dados levantados a partir de uma perspectiva diferente, com foco principal na visão das mulheres indígenas, abrindo caminho para uma prática de saúde que transcenda o campo biomédico. Deste modo, este artigo tem como objetivo conhecer as práticas em saúde sexual e reprodutiva de mulheres da etnia Xukuru do Ororubá.

\section{Material e métodos}

Trata-se de um estudo descritivo exploratório, com abordagem qualitativa, que se utiliza da Teoria Transcultural do Cuidado, a qual operacionaliza a etnoenfermagem como proposta metodológica ${ }^{8}$. No contexto da metodologia qualitativa aplicada à saúde, emprega-se a concepção trazida das ciências humanas, segundo a qual não se busca estudar o fenômeno em si, mas entender seu significado individual ou coletivo para a vida das pessoas ${ }^{10}$.

O local de estudo foi a Aldeia de Cimbres, terra indígena Xukuru, localizada na Serra do Ororubá, município de Pesqueira (PE). A história do povo Xukuru do Ororubá é marcada por um passado recente de muitas disputas e conflitos territoriais, resultando em perseguiç̧ões, expulsões e mortes de indígenas por parte de fazendeiros ${ }^{11,12}$. Atualmente, a população é estimada em 7.677 indígenas ${ }^{13}$, habitando 24 aldeias, e cada aldeia é constituída por um grupo de famílias. No que diz respeito aos traços étnicos e culturais, é um povo falante da língua portuguesa, que guarda, ainda, antigos vocábulos nativos. Vivencia a religião indígena e católica, expressas nas festas religiosas e nos rituais anuais, e, principalmente, na dança do Toré11,12.

Segundo Leininger ${ }^{8}$, a operacionalização da coleta de dados, por meio da etnoenfermagem, pressupõe o desenvolvimento de capacitadores (facilitadores), que auxiliam na investigação sobre a cultura e o cuidado. Na presente pesquisa, foram utilizados três capacitadores para a obtenção dos dados: 1- Observação-Participação-Reflexão (OPR), com registro em diário de campo; 2- Formulário do perfil socioeconômico; e 3- Entrevista semiestruturada.

A fim de garantir o cumprimento das questões éticas, com a anuência do Conselho Indígena de Saúde Xukuru do Ororubá (Cisxo) e do Conselho Distrital de Saúde Indígena (Condisi), este estudo foi submetido à apreciação e aprovado pelo Comitê de Ética em Pesquisa do Complexo Hospitalar Huoc/ Procape e da Comissão Nacional de Ética em 
Pesquisa (Conep), parecer $n^{\circ}$ 2.116.494/17. Ressalta-se que todas as depoentes aceitaram, livremente, participar da entrevista e, após receberem todos os esclarecimentos pertinentes ao estudo, assinaram o Termo de Consentimento Livre e Esclarecido (TCLE). Resguardando a identidade das participantes da pesquisa, foram utilizados os seguintes codinomes de pássaros do tupi-guarani: Uirapuru, Tangará, Nhambu, Mutum, Maritaca, Maguari, Macuco, Jaçanã, Gûyrá, Groló, Graúna, Grapirá, Acaé, Anu, Bairari, Sabiá, Cachimbó e Jacu, preservando a confidencialidade das informações.

As entrevistas aconteceram nas dependências da Escola Indígena Mílson e Nílson, e do Posto de Saúde - Aldeia Cimbres. Para garantir a qualidade dos dados, todas foram gravadas por meio de aparelho eletrônico. Participaram 18 depoentes, que se adequaram aos critérios de inclusão delimitados: mulheres na faixa etária de 18 a 49 anos, pertencentes à etnia Xukuru do Ororubá e residentes no território indígena. Vale destacar que a quantidade de mulheres depoentes foi determinada após a obtenção do ponto da saturação. A saturação é operacionalmente definida como a suspensão da inclusão de novas participantes quando os dados obtidos passam a apresentar, na avaliação das pesquisadoras, uma certa redundância ou repetição, não sendo considerada relevante a persistência na coleta de dados ${ }^{\mathbf{1 4}}$.

Os dados também foram organizados com base na etnoenfermagem ${ }^{8}$. Esta pressupõe análise sistemática, profunda e rigorosa da pesquisa qualitativa, dividida em quatro fases. A primeira é conhecida como a relação dos dados coletados. Neste momento, as pesquisadoras reúnem todo o material da coleta para uma primeira leitura. Já a segunda fase se baseia na identificação dos descritores e seus componentes. É o momento de caracterizar as falas das informantes, com o objetivo de identificar as semelhanças e diferenças quanto às afirmações e aos comportamentos encontrados. Na terceira fase de análise do padrão contextual, é realizada avaliação criteriosa dos dados, buscando a saturação de categorias para demonstrar os padrões do cuidado com respeito aos significados no contexto, na consistência e credibilidade. Por fim, há a fase denominada 'temas principais', em que se discutiram as descobertas da pesquisa.

Foram codificadas quatro categorias analíticas, que contemplaram as categorias nativas/ êmicas identificadas nos dados coletados: 1) Mulheres da etnia Xukuru do Ororubá e o lugar que ocupam;2) Políticas de saúde e seu impacto na vida das mulheres indígenas; 3 ) Práticas em saúde sexual e reprodutiva; 4) Enfermagem: promoção à saúde e empoderamento.

\section{Resultados e discussão}

Foi traçado o perfil das mulheres para facilitar a compreensão das dimensões das estruturas cultural e social do grupo em estudo. Entre as 18 participantes, 7 tinham entre 20 e 28 anos de idade, e 11 tinham entre 32 e 48 . Percebe-se a presença de duas gerações de mulheres indígenas no estudo. Segundo Laraia ${ }^{15}$, a cada geração, é possível vislumbrar mudanças culturais em uma coletividade, sendo a diferença de idade, então, de grande utilidade para a pesquisa.

Todas as entrevistadas eram cisgêneras e heterossexuais. Foi identificada apenas uma mulher transexual na aldeia, que, por ser menor de 18 anos de idade, não preencheu todos os critérios de inclusão e ficou fora da pesquisa. Vale informar que ela fez referência a uma indígena cisgênera e lésbica que, no momento, não habitava mais a aldeia. A identidade de gênero e a orientação sexual dos povos indígenas são temas pouco explorados nos estudos que compõem diversas áreas, inclusive porque, de modo geral, as especificidades da comunidade de Lésbicas, Gays, Bissexuais, Travestis e Transexuais (LGBT) são bastante negligenciadas e invisibilizadas ${ }^{\mathbf{1 6}}$.

Quanto à escolaridade, seis mulheres possuíam o ensino fundamental incompleto; cinco, o ensino médio incompleto; seis, o ensino médio completo; e apenas uma possuía ensino 
superior incompleto. As principais ocupações das participantes eram: dona de casa, agente de saúde, agricultora e merendeira. A falta de estudos completos espelha a realidade socioeconômica em que se encontram.

Em relação ao estado civil, entre as $18 \mathrm{mu}-$ lheres participantes, predominaram as casadas (14), que conviviam com seus parceiros sexuais em domicílios habitados por 2 a 9 pessoas, entre filhos e demais parentes. Observa-se que o casamento ainda é o esperado para a mulher: monogâmico e organizado dentro do sistema patriarcal.

\section{Mulheres da etnia Xukuru do Ororubá e o lugar que ocupam}

Leininger ${ }^{8}$ sempre menciona a importância de utilizar, além da teoria e da técnica, o ouvir, o observar, o sentir. Com isso, os primeiros resultados vieram em uma aproximação com o campo de pesquisa, ainda no início da construção do projeto que originou o presente artigo. Na XVI Assembleia do Povo Xukuru do Ororubá, ocorrida no ano de 2016, o Cacique Marcos Xukuru falou para um grupo sobre a construção do projeto de vida do povo e o enfrentamento à conjuntura de ataques aos direitos indígenas, e encerrou a fala proferindo sua palavra de ordem: ' $\mathrm{E}$ diga ao povo que avance'. Perante esse discurso, buscou-se observar os avanços no papel desempenhado pelas mulheres indígenas no cotidiano das aldeias e na luta do povo.

Em uma análise externa, percebeu-se que, não muito distante da realidade de outros povos de Pernambuco, como trazido por Leal, et al. $^{\mathbf{2}}$, a maioria das lideranças são ocupadas por homens e, no geral, as mulheres apenas participam da assembleia de forma indireta, desempenhando trabalhos 'ditos femininos', como os de cozinha. A força das estruturas da dominação de gênero estabelece o lugar sócio-historicamente instituído para o feminino, que, de acordo com a pesquisadora Sorj"17, compreende as responsabilidades domésticas e familiares. O uso do facilitador da OPR possibilitou um mover gradual da observação para a participação, e desta para a reflexão, confirmando os resultados durante as entrevis$\operatorname{tas}^{8}$. As falas das mulheres evidenciam o lugar feminino quando trazem a responsabilização das mães sobre as práticas e decisões das filhas, no tema da saúde sexual e reprodutiva.

Não, nunca tinha esse diálogo [a mãe], não tinha. Não é como hoje, que a gente senta com nossos filhos, principalmente as nossas meninas, e fala 'Filha, usa camisinha', prevenindo não só contra filho, mas doenças transmissíveis. Tudo isso, a gente senta e conversa. Aquilo que minha mãe não conversou comigo, eu sempre passo pra elas [filhas]. (Graúna).

O que minha mãe dizia, e diz, é que, se a moça fizer isso [sexo antes do casamento] com o namorado, ela vai ficar falada. Não faça isso, porque, se fizer isso, eles não querem mais, e os outros não querem. (Anu).

Eu não sei se elas [filhas] vão dar pr'a gente ou outro tipo de coisa. Mas quando elas crescerem, eu sempre vou sentar pra conversar, dar o exemplo que minha mãe não me deu [...] ela sempre foi uma mãe ausente. (Tangará).

Frequentemente, ressalta-se a importância do feminino dentro dos povos indígenas, seja quando se fala da Mãe Terra, que é ente feminino, seja se referindo às mulheres e aos papeis que ocupam, com bons exemplos de mulheres indígenas que estão nas lideranças, presentes inclusive na coordenação executiva da Articulação dos Povos Indígenas do Brasil ${ }^{2}$. Contudo, a construção social de gênero, que define a relação entre homens e mulheres no que tange a padrões de comportamento e aos papeis atribuídos, desagua em uma relação de poder desfavorável para as mulheres, tudo isso com base na biologização do corpo ${ }^{18}$. O que é mais nebuloso dentro da comunidade indígena é a dificuldade que existe de reconhecer a desigualdade de gênero, como Barros Jr. ${ }^{19}$ traz em seu texto, falando especificamente do povo Xukuru do Ororubá. 
Para o avanço das pautas das mulheres indígenas, é necessário reconhecer que o machismo e o patriarcado são abrangentes, fortes e continuam passando de geração em geração, e ainda fazem parte do dia a dia das sociedades indígenas e não indígenas. Há as mazelas do homem branco, mas o que parece mais complicado é tratar e reconhecer a violência no ambiente familiar e comunitário.

Ele [ex-marido] é muito mulherengo. Bebia bastante, começou a me bater. (Acaé).

Tive relações com ele em dezembro, e foi a primeira vez, também, que eu tinha bebido. Nunca tinha bebido. Aí, me perdi também, não senti nada [...] eu fui saber no outro dia o que tinha acontecido, porque ele me disse [...] quando ele falou eu acreditei, porque eu estava dolorida [...] de lembrar como foi, não lembro. Mas eu sei que não houve abuso, porque foi dentro de casa, e estava meu pai e minha mãe dormindo. Então, quer dizer que, se tivesse sido abuso de algum jeito, meu pai e minha mãe teriam escutado [...] praticamente eu me juntei a pulso, porque eu não queria. (Grapirá).

A preocupação com relatos como esses vem promovendo debates, ainda que limitados, sobre o tema da violência, e entende-se que as justificativas para essas práticas com discursos baseados em 'costume', valores 'tradicionais' e na 'cultura' precisam ser desconstruídas ${ }^{20}$. Avaliar o que vale a pena resguardar da estrutura de gênero tradicional e que aspectos podem mudar representa um grande desafio a ser enfrentado, não apenas pelo movimento de mulheres indígenas, mas por cada povo em particular².

\section{Políticas de saúde e seu impacto na vida das mulheres indígenas}

Foi criado, em 1999, o Subsistema de Saúde Indígena, resultado das mudanças no sistema brasileiro de saúde pública que vinham ocorrendo desde a década de 1980, passando inclusive pela construção da Constituição cidadã ${ }^{21}$. Em 2002, foi instituída a Política Nacional de Atenção à Saúde dos Povos Indígenas (PNASPI), com o intuito de compatibilizar os direitos diferenciados, constitucionalmente garantidos aos povos indígenas, à Lei Orgânica da Saúde, que, por sua vez, não menciona as questões atinentes à relação entre gênero e saúde 22,23 .

Quanto ao acesso, iniciou-se uma expansão dos serviços de saúde, buscando alcançar as áreas indígenas. No cenário de hoje, ainda não há uma realidade homogênea entre os territórios indígenas, mas, no território trabalhado no presente estudo, é possível notar o impacto desta expansão.

[...] o posto daqui, ele ajudou muito a área indígena, porque o atendimento d'a gente aqui era tudo em Pesqueira. Era muita dificuldade pra marcar uma consulta, marcar um exame. (Grapirá).

Agora não, agora é muito bom [sobre o acesso à saúde] [...] até o carro vai pegar as gestantes lá onde a gente mora [qualquer aldeia] quando é tempo de pré-natal. Se tornou mais fácil. Já no meu tempo, era mais difícil. (Maritaca).

No universo feminino, houve, em 1983, a criação do Programa de Atenção Integral à Saúde da Mulher (Paism), que estabeleceu a saúde reprodutiva como prioridade de ação política. No âmbito desse programa, a mulher passou a ser compreendida como um sujeito de direitos. E como um desdobramento do Paism, foi lançada, em 2004, a Política Nacional de Atenção Integral à Saúde da Mulher (PNAISM). Tal política, orientada pelos princípios de integralidade, equidade e universalidade que formam o Sistema Único de Saúde (SUS), passou a considerar o enfoque de gênero, de raça, de etnia e geracional ${ }^{23}$.

O PNAISM identifica a necessidade de articulação com outras áreas técnicas, além da proposição de novas ações, mas, desde 2004, são ensaiadas iniciativas para a saúde das mulheres indígenas, sem sucesso. Por isso, percebeu-se que o avanço proposto pela política não chegou para essas mulheres, conferindo 
uma atenção que perpetua o aprisionamento da mulher ao lugar maternal ${ }^{23}$. Nos relatos do presente estudo é possível perceber esta visão restrita quando se faz a pergunta 'Pra você, o que significa saúde sexual e reprodutiva?’:

Assim [...] o que eu penso é sobre família, como é a convivência, como é ser mãe nova, terminar o estudo e ter filho cedo. (Graúna).

Eu acho que me sinto uma mulher realizada. Eu tenho minhas filhas, meu marido. Primeiro lugar, saúde. Depois, a pessoa conhecer a pessoa que quer ter os filhos, e tem os filhos. (Anu).

Saúde e sexo reprodutivo, no meu ponto de vista [...] a saúde, a gente teve o sexo reprodutivo. Primeiro, a gente tem que ter a saúde. Se a gente não tem a saúde, como é que a gente vai reproduzir? Nós, doentes, não podemos reproduzir, porque a gente sabe que vai ter a formação de um ser dentro de nós. No meu ponto de vista, é isso daí. (Jaçanã).

Parte do grande desafio de ampliar o horizonte feminino, para além da tarefa reprodutiva, é a própria ideia do que significa seu corpo e a relação com ele. As falas levantadas vêm, em sua maioria, carregadas com a ideia de que seus corpos são propriedades dos homens, seja quando relatam o despertar sexual com o homem como protagonista, ou com a utilização de termos como 'me entreguei' e 'me perdi'.

Então, com 13 anos, me entreguei a ele [...] me juntei com ele [...] mexeu com a moça, tem que casar. (Graúna).

Aí, eu completei 15 anos em novembro. Me perdi em dezembro, tive relações com ele em dezembro. (Grapirá)

Na verdade, eu ainda não tinha me perdido, porque é assim que se fala: 'Perdida'. (Acaé).

Diretamente atrelado à representação do corpo, está o fato de que grande parte das mulheres deste estudo é ou foi casada com o primeiro homem com quem se relacionou, mesmo que muitas delas tenham expressado que não queriam, ou que se arrependeram.

Assim, terminei casando sem gostar, só por causa da família, que gostava muito dele, entendeu? (Acaé).

Meu esposo, só! Minha primeira relação foi com ele. (Jacu).

Se fosse hoje, estava casada não [...] não que a minha vida de casada seja ruim. Mas é porque foi tão rápido, eu perdi minha juventude. (Graúna).

O sistema reprodutivo acaba por restringir as mulheres mais intensamente quando precisam se responsabilizar sozinhas pelas crianças.

Quando eu descobri que eu estava grávida, eu tive que voltar [de São Paulo], abandonar tudo lá. Ele [marido] é uma pessoa assim, 'rugida', não tinha diálogo com ele [...] nunca foi de dar muito apoio. (Graúna).

[...] e queria porque queria [ter filho], ele também era muito novo e, você sabe, devido à minha idade e tudo, eu pensava: 'Se eu não tiver um filho com ele, claro que ele vai tentar fazer em outra pessoa, que ele quer muito um filho'. (Grapirá).

Tinha ido pra um forró [o marido] a noite todinha [...] deixou eu em trabalho de parto [...] foi embora, chegou de manhã. (Acaé).

Aprisionadas nessa significação de corpo e na dependência da figura masculina, as participantes demonstraram que não conseguiam visualizar outro tipo de vivência da sexualidade. Ou seja, o exercício saudável da sexualidade não passava pela descoberta das áreas do corpo que poderiam lhes proporcionar prazer por elas mesmas, e muito menos se aproximavam da prática sexual com outras mulheres, o que se reflete nas falas das entrevistadas, quando respondem com muita convicção à pergunta 'Você só se relacionou/relaciona com homens?': 
Só com homem, graças a Deus. (Groló).

Com certeza, sim. Não que eu tenha preconceito, entendeu? Mas só com homens. (Anu).

Lógico, só com homens. (Jaçanã).

Verifica-se a necessidade de uma releitura das políticas públicas de saúde da mulher indígena para a consolidação de direitos, pois o acesso à saúde foi só o primeiro passo de um longo caminhar. Em um horizonte ainda turvo, a Estratégia Saúde da Família (ESF) constitui-se em 'locus' privilegiado de desenvolvimento das questões de gênero em saúde, buscando garantir o direito pleno das mulheres decidirem sobre seus corpos e vidas ${ }^{\mathbf{2 4}}$.

\section{Práticas de saúde sexual e reprodutiva}

Para compreender a saúde das pessoas e da comunidade, torna-se necessário analisar suas práticas a partir da conjuntura onde elas tomam forma, pois cada contexto possui características específicas. Aqui, o termo 'práticas de saúde' é utilizado como sinônimo de qualquer forma de cuidado, não apenas da prática biomédica, abrangendo práticas advindas da cultura popular, tais como o benzimento e as ligadas a religiões ${ }^{25}$.

O povo Xukuru do Ororubá, por ser um grupo que está em contato permanente com pessoas não índias, assim como os Truká, encontra-se em uma situação sanitária e de saúde semelhante à da população geral do Agreste e do Sertão pernambucano ${ }^{26}$. Mesmo assim, possui especificidades que situam o tema das práticas de saúde em um contexto diferenciado de compreensão sobre saúde, doença e processos de cura.

De acordo com os depoimentos, constatou-se que as mulheres Xukuru do Ororubá fazem uso regular da biomedicina e da medicina indígena, simultaneamente.

Eu sempre tomo [chás]. Por isso, quando eu faço prevenção, graças a Deus, não dá nada, porque eu me cuido. (Uirapuru).

Olha, eu uso o remédio que o médico passa e também uso remédio caseiro, que dizem que é bom. (Mutum).

Pra corrimento, eu tomo casca de pau na água [...] às vezes, eu uso a pomada; às vezes, o comprimido. (Maritaca).

A relação existente entre a sabedoria popular e as práticas de cuidado está diretamente ligada à utilização de plantas medicinais, que é uma das mais antigas práticas populares em saúde, conhecida predominantemente por mulheres ${ }^{\mathbf{2 7}}$.

A maioria das entrevistadas utiliza as plantas sempre que tem algum sintoma ginecológico - destacando-se o corrimento vaginal, outras afecções mencionadas foram infecção, coceira e atraso menstrual. Entre as ervas medicinais usadas, estão: quixabeira, aroeira, cajueiro roxo, chifre de bode, cidreira, barba-de-timão, cabacinha e quebra-faca. $\mathrm{O}$ preparo das plantas por todas as mulheres é feito por infusão, em banho de assento ou elas as ingerem através de chás.

Quixabeira é uma planta anti-inflamatória, ela faz tratamento de colo uterino. Eu já alcancei pessoas aqui não tomar pílula, não fazer uso de camisinha, mas ter o esposo dela, e elas fazerem o uso da água da quixabeira. (Jaçanã).

Tem o chifre de bode, não sei se você sabe [...] é bom pra inflamação. A gente toma, a gente se banha. Serve bastante. Para mim, serve mais do que os remédios de farmácia. (Jacu).

Leininger ${ }^{8}$ assinala que o cuidado é dividido entre popular e profissional. O cuidado popular refere-se ao conhecimento culturalmente apreendido e transmitido. Esta transmissão é feita de modo tradicional entre as gerações, são práticas de cuidado desenvolvidas e compartilhadas entre as mulheres. Entretanto, 
percebe-se que as mulheres indígenas com menos de 30 anos conhecem menos, e já quase não utilizam os modos/cuidados culturalmente apreendidos.

É porque, assim, eu fui criada com meus avós, e tudo deles era erva [...] era mais minha avó, que minha avó era mais rezeira. A gente estava com dor de barriga, ia no quintal, pegava erva-cidreira, capim-santo, erva-doce. (Graúna).

Temos uma rezadeira e nossa curandeira por aqui. Aí diz que, se tiver um corrimento ou tiver com alguma coisa, toma chifre de bode, banho de água de caju. (Anu).

A biomedicina se expressa de forma mais incisiva no uso de métodos contraceptivos, utilizados para evitar uma gravidez indesejada. Destacou-se o uso da camisinha e da pílula. Além disso, chamou a atenção o apelo à laqueadura.

Eu pretendo colocar um DIU [dispositivo intrauterino]. A doutora falou que depois de quatro meses eu coloco, porque eu não posso me operar, porque eu sou muito nova. (Tangará).

Com 19 anos, eu fiz minha ligação. (Graúna).

Ainda queria desfazer a cirurgia [...] tinha como fazer isso, mas eu desisti. Deus só me deu os dois, deixa eu só com os dois mesmo, que eu não vou arrumar mais problema. (Acaé).

Esse abdicar da vida reprodutiva dentro de um centro cirúrgico é visto como saída eficaz, rápida e desprovida de preocupações posteriores. Contudo, a precipitação e o arrependimento aparecem nas narrativas e, segundo Fontenele e Tanaka ${ }^{28}$, seria importante que as mulheres fossem mais bem orientadas sobre a laqueadura e outros métodos, visto que o acesso às informações pode promover mais segurança ante as escolhas.

As mulheres indígenas têm acesso e utilizam variados sistemas alternativos de saúde, contudo, o fazem sem uma real articulação. Assim, é preciso conhecer e valorizar essas práticas, e realizar uma discussão mais aprofundada sobre a inter-relação do cuidado tradicional e as intervenções no campo da biomedicina ${ }^{26-29}$.

\section{Enfermagem: promoção à saúde e empoderamento}

Leininger ${ }^{\mathbf{8}}$ define a enfermagem como uma profissão focalizada no fenômeno e nas atividades do cuidado, do comportamento humano e suas variações determinadas pela cultura. Todavia, quando o tema da consulta de enfermagem foi problematizado com as participantes, percebeu-se a fragmentação da assistência prestada às mulheres, basicamente em pré-natal e prevenção de câncer de colo de útero.

Em um estudo realizado por Marinelli et al. ${ }^{30}$, sobre a assistência à população indígena e as dificuldades encontradas por enfermeiras e enfermeiros, constataram-se, entre os entraves, a falta de treinamento específico para o trabalho com indígenas, dificuldade de comunicação, as barreiras geográficas, condições de trabalho não satisfatórias e a aceitação do corpo profissional, por parte das pessoas indígenas.

Eu nunca fiz [o preventivo] na cidade. Tem gente que faz na cidade porque tem vergonha, tem num sei o quê. Mas eu acho que, pra saúde da pessoa, a pessoa não pode que ter vergonha, tem que fazer, pra evitar algumas coisas, doenças. (Uirapuru).

Muitas delas têm preconceito. É por vergonha, e elas têm um pouquinho de receio. Elas gostam muito da enfermeira e elas ficam meio constrangidas de ver a cara da enfermeira. (Jaçanã).

As equipes de saúde são desafiadas a desenvolver a dinâmica da sensibilidade cultural, uma consciência das semelhanças e diferenças culturais $^{8}$. Neste caso, a enfermagem vem conquistando um espaço importante, como profissão educadora, no âmbito da saúde indígena. 
Eles fazem palestra com a comunidade, para os jovens; eles explicam as doenças que são transmissíveis. Fazem as palestras na escola também. Eles dão os preservativos em casa e na escola. (Gûyrá).

Acho que eles já passam as informações corretas. Eles trabalham muito em cima dessas doenças e eles conversam bastante com os jovens. Pra mim, já é o suficiente, que, no meu tempo, não tinha essas palestras. (Nhambu).

Entretanto, é preciso desmistificar o tema e abordar não apenas os riscos do exercício da sexualidade, mas também o prazer, os sentimentos, o respeito e a responsabilidade envolvidos. Para a realização de uma enfermagem que esteja pautada em uma abordagem transcultural, urge o redirecionamento das práticas em saúde da mulher. É necessário repensar o modelo de assistência praticado, priorizando os atos cuidadores e a autonomia das pessoas ${ }^{\mathbf{3 1}}$.

Carvalho e Gastaldo ${ }^{32}$ sugerem o exercício de uma prática profissional guiada pelo entendimento da usuária enquanto cidadã portadora de direitos, que valoriza a parceria entre profissionais, pessoas individuais e comunidades, em substituição a uma prática alienada e autoritária, na qual as pessoas que trabalham na saúde são simplesmente provedoras de serviços, e a usuária, uma consumidora. Nesta instância, o 'empoderar-se' não corresponde apenas a um ato psicológico, individual, mas a um ato social e político.

\section{Considerações finais}

Quando se utiliza a Teoria Transcultural do Cuidado para delimitar práticas de saúde, questiona-se, antes, o modelo social e cultural. Diante da discussão realizada no presente estudo, percebe-se que o lugar social hegemonicamente ocupado pelas mulheres indígenas faz delas as que mais sofrem frente às perdas de direitos de seu povo e às mazelas que adentraram e adentram na comunidade indígena.
Na atual conjuntura política do Brasil, não há espaço para a hesitação, é preciso avançar para além dos papeis historicamente atribuídos ao feminino, se organizar e conquistar espaços de fala e de representação.

Compreendendo esse contexto das mulheres Xukuru do Ororubá, compreende-se também a herança de medos, impedimentos e dificuldades na abordagem da saúde sexual e reprodutiva. A consciência das condições sócio-históricas que se inserem em suas trajetórias permitirá às mulheres indígenas derrubarem barreiras e repensarem o modelo de saúde praticado. Pois o que se tem observado é uma sobreposição gradual da biomedicina à medicina indígena, sem a valorização dos atos cuidadores e da autonomia das pessoas.

Frente a essa conjuntura, a profissão da enfermagem destacou-se com grande potencial para o cuidado transcultural. A escuta, a responsabilização e a criação de vínculos com a inserção da abordagem de gênero oferecem à mulher possibilidades de empoderar-se. Assim, a enfermeira e o enfermeiro seriam facilitadores do cuidado à saúde, como pontes que interagem e estabelecem intercomunicações da biomedicina com a medicina tradicional. Sempre lançando mão de pluralidades terapêuticas, capazes de estimar os chás e banhos da cultura Xukuru do Ororubá sem deixar de oferecer novas tecnologias para o cuidado da saúde sexual e reprodutiva.

Por fim, fica a análise de que o despertar das mulheres indígenas consiste ainda em um processo embrionário, mas que, mesmo com todos os obstáculos, vem avançando, inclusive quando busca a aproximação com o cotidiano das mulheres nas bases, através de mulheres indígenas multiplicadoras e questionadoras dos motes de gênero, saúde e de seus direitos. Tais mulheres forjam-se como protagonistas de escolhas, que vão desde o seu papel dentro da comunidade até o direito de vivenciar livremente sua saúde sexual e reprodutiva. Parte importante de tais desafios é firmar que fortalecer a luta das mulheres indígenas é fortalecer a luta de seu povo, para que, assim, possam continuar avançando e alcem voo sem temer. 


\section{Colaboradores}

Araujo MRA (0000-0002-9565-6285)* e Tavares MS (0000-0002-5771-7382)* contribuíram para a concepção do estudo, coleta e análise de dados, e elaboração do artigo. Souza VRFP (0000-0003-4673-378X)* e Bezerra DO (0000-0003-2380-0820)* contribuíram para o delineamento do estudo, interpretação dos dados, e revisão do artigo.

\section{Referências}

1. Oliveira GC. Duas décadas de luta feminista antirracista pelos direitos sexuais e reprodutivos. In: Oliveira GC, Campos CH, organizadores. Saúde reprodutiva das mulheres: direitos, desafios e políticas públicas. Brasília, DF: Ars Ventura Imagem e Comunicação; 2009. p. 15-30.

2. Leal C, Eneida H, Andrade LE. Algumas considerações sobre o vivido. In: Leal C, Eneida H, Andrade LE, organizadores. Guerreiras: a força da mulher indígena. Olinda: Centro de Cultura Luiz Freire; 2012. p. 6-29.

3. Luciano GS. Gênero. In: Luciano GS. O índio brasileiro: o que você precisa saber sobre os povos indígenas no Brasil de hoje. Brasília, DF: Ministério da Educação; 2006. p. 208-215.

4. Verdum R. Mulheres indígenas, direitos e políticas públicas. Brasília, DF: Inesc; 2008.

5. Rede Grumin de Mulheres Indígenas. Mesa de Trabalho Local e Regional Rumo ao Fórum Nacional de Mulheres Indígenas. Itaipu; 2008.

6. Brasil. Ministério da Saúde. Saúde sexual e saúde reprodutiva. Cadernos de atenção básica. Brasília, DF: Ministério da Saúde; 2013. (n. 26).
7. Waldow VR. Atualização do cuidar. Aquichán; 2008; 8(1):85-96.

8. Leininger MM, Farland MR. Culture care diversity and universality: a worldwide nursing theory. 2. ed. New York: Jones and Bartlett Publishers; 2006.

9. Camargo FCM, Lima RFS, Santos AM, et al. A aplicabilidade da teoria do cuidado cultural por enfermeiras nos periódicos de saúde do Brasil (1992-2011). Rev. Pesqui. Cuid. Fundam. 2014; 6(1):1743-1755.

10. Turato ER. Métodos qualitativos e quantitativos na área da saúde: definições, diferenças e seus objetos de pesquisa. Rev. Saúde Públ. 2005; 39(3):507-514.

11. Almeida AWB, Marin REA, Fialho V. Nova cartografia social dos povos e comunidades tradicionais do Brasil: Xukuru do Ororubá - PE. Manaus: UEA Edições; 2012.

12. Fialho V. As fronteiras do ser Xukuru. Recife: FUNDAJ. Ed. Massangana; 1998.

13. Instituto Brasileiro de Geografia e Estatística. Censo Demográfico 2010: Características Gerais dos Indígenas - Resultados do Universo. Rio de Janeiro: IBGE; 2010.
*Orcid (Open Researcher and Contributor ID). 
14. Pires AP. Amostragem e pesquisa qualitativa: ensaio teórico e metodológico. In: Poupart J, Deslauriers JP, Groulx LH, et al., organizadores. A pesquisa qualitativa: enfoques epistemológicos e metodológicos. Petrópolis: Vozes; 2008. p. 154-211.

15. Laraia RB. Cultura: um conceito antropológico. 18. ed. Rio de Janeiro: Jorge Zahar; 2005.

16. Angonese M, Lago MCS. Direitos e saúde reprodutiva para a população de travestis e transexuais: abjeção e esterilidade simbólica. Saúde Soc. 2017; 26(1):256270 .

17. Sorj B. Trabalho remunerado e trabalho não-remunerado. In: Venturi G, Recamán M, Oliveira S. A mulher brasileira nos espaços público e privado. São Paulo: Fundação Perseu Abramo; 2004. p. 107-119.

18. Scott JW. Gênero: uma categoria útil de análise histórica. Porto Alegre: Educação e Realidade; 1990.

19. Barros Junior F. Organizações tradicionais e políticas públicas contemporâneas: avanços e retrocessos na autonomia da mulher Xukuru. In: Sacchi A, Gramkow MM. Gênero e povos indígenas. Brasília, DF: Fundação Nacional do Índio; 2012. p. 128-139.

20. Verdum R. Mulheres Indígenas na luta pela proteção e promoção dos seus Direitos [internet]. Brasília, DF: Inesc; 2010 [acesso em 2017 jun 26]. Disponível em: http://www.inesc.org.br/noticias/noticias-do-inesc/2010/novembro/mulheres-indigenas-na-luta-pela-protecao-e-promocao-dos-seus-direitos.

21. Azevedo ALM, Gurgel IGD, Tavares MA. O poder de acessar a saúde: uma análise do acesso à saúde na etnia indígena Xukuru do Ororubá, Pesqueira (PE). Cad. Saúde coletiva. 2014; 22(3):275-280.

22. Brasil. Ministério da Saúde. Política nacional de atenção à saúde dos povos indígenas. 2. ed. Brasília, DF: Fundação Nacional de Saúde; 2002.

23. Ferreira LO. Saúde e relações de gênero: uma reflexão sobre os desafios para a implantação de políti- cas públicas de atenção à saúde da mulher indígena. Ciênc. Saúde Colet. 2013; 4(18):1151-1159.

24. Benites APO, Barbarini N. Histórias de vida de mulheres e saúde da família: algumas reflexões sobre gênero. Psicol. Soc. 2009; 21(1):16-24.

25. Oliveira MW, Moraes JV. Práticas populares de saúde e a saúde da mulher. Rev. APS. 2010; 13(4):412-420.

26. Vieira HTG, Oliveira JEL, Neves RCM. A relação de intermedicalidade nos Índios Truká, em Cabrobó Pernambuco. Saúde Soc. 2013; 22(2):566-574.

27. Muller CP, Araujo VE, Bonilha ALL. Possibilidade de inserção do cuidado cultural congruente nas práticas de humanização na atenção à saúde. Rev. Eletrônica Enferm. [internet]. 2007 [acesso 2017 jun 17]; 9(3):858-865. Disponível em: https://www.fen.ufg.br/ rVevista/v9/n3/v9n3a24.htm.

28. Fontenele CV, Tanaka ACD. O fio cirúrgico da laqueadura é tão pesado!: laqueadura e novas tecnologias reprodutivas. Saúde Soc. 2014; 23(2):558-571.

29. Pereira ER, Biruel EP, Oliveira LSS, et al. A experiência de um serviço de saúde especializado no atendimento a pacientes indígenas. Saúde Soc. 2014; 23(3):10771090.

30. Marinelli NP, Nascimento DF, Costa AIP, et al. Assistência à população indígena: dificuldades encontradas por enfermeiros. Revista Univap. 2012; 18(32):5265.

31. Malta DC, Merhy EE. O percurso da linha do cuidado. Interface. 2010; 14(34):593-605.

32. Carvalho SR, Gastaldo D. Promoção à saúde e empoderamento: uma reflexão a partir das perspectivas crítico-social pós-estruturalista. Ciênc. Saúde Colet. 2008; 13(2):2029-2040.

Recebido em 24/04/2019

Aprovado em 14/11/2019

Conflito de interesses: inexistente

Suporte financeiro: não houve 